\title{
Is cognitive functioning 1 year poststroke related to quality of life domain?
}

Citation for published version (APA):

Verhoeven, C. L. M., Post, M. W. M., Schiemanck, S. K., van Zandvoort, M. J. E., Vrancken, P. H., \& van Heugten, C. M. (2011). Is cognitive functioning 1 year poststroke related to quality of life domain? Journal of Stroke \& Cerebrovascular Diseases, 20(5), 450-458.

https://doi.org/10.1016/j.jstrokecerebrovasdis.2010.02.018

Document status and date:

Published: 01/01/2011

DOI:

10.1016/j.jstrokecerebrovasdis.2010.02.018

Document Version:

Publisher's PDF, also known as Version of record

Document license:

Taverne

Please check the document version of this publication:

- A submitted manuscript is the version of the article upon submission and before peer-review. There can be important differences between the submitted version and the official published version of record.

People interested in the research are advised to contact the author for the final version of the publication, or visit the DOI to the publisher's website.

- The final author version and the galley proof are versions of the publication after peer review.

- The final published version features the final layout of the paper including the volume, issue and page numbers.

Link to publication

\footnotetext{
General rights rights.

- You may freely distribute the URL identifying the publication in the public portal. please follow below link for the End User Agreement:

www.umlib.nl/taverne-license

Take down policy

If you believe that this document breaches copyright please contact us at:

repository@maastrichtuniversity.nl

providing details and we will investigate your claim.
}

Copyright and moral rights for the publications made accessible in the public portal are retained by the authors and/or other copyright owners and it is a condition of accessing publications that users recognise and abide by the legal requirements associated with these

- Users may download and print one copy of any publication from the public portal for the purpose of private study or research.

- You may not further distribute the material or use it for any profit-making activity or commercial gain

If the publication is distributed under the terms of Article $25 \mathrm{fa}$ of the Dutch Copyright Act, indicated by the "Taverne" license above, 


\title{
Is Cognitive Functioning 1 Year Poststroke Related to Quality of Life Domain?
}

\author{
Clara L. M. Verhoeven, Msc, ${ }^{*}$ Marcel W. M. Post, PhD, †† \\ Sven K. Schiemanck, MD, PhD, $\uparrow \S$ Martine J. E. van Zandvoort, $\mathrm{PhD}, \boldsymbol{\uparrow} \|$ \\ Peter H. Vrancken, MSc, ${ }^{*}$ and Caroline M. van Heugten, $\mathrm{PhD}, \dagger^{* *}$
}

\begin{abstract}
Previous studies on the association between poststroke cognitive impairment and quality of life (QoL) have shown divergent results. In this study, we investigated the relationships between cognitive functioning and various QoL domains at 1 year poststroke. This was a cross-sectional study, examining 92 patients at 1 year poststroke. Cognitive functioning was measured with a neuropsychological test battery covering language, attention and psychomotor function, memory, visuoperception, and neglect. QoL domains were functional independence (Barthel Index), social participation (Frenchay Activities Index), depressive mood (Center for Epidemiological Studies Depression Scale), and life satisfaction (Life Satisfaction Questionnaire). Bivariate and multivariate relationships between cognitive and QoL variables were analyzed, the latter both with and without controlling for demographic variables and motor impairment. The prevalence of cognitive impairments varied between $19.3 \%$ (neglect) and $72 \%$ (attention and psychomotor function). Correlations between cognitive functioning and QoL were strongest for social participation $(0.41-0.60, P<$ $.01)$ and functional independence $(0.13-0.58, P<.05)$. The percentages of variance explained by the total cognition score were $19 \%$ for functional independence, $40 \%$ for participation, $8 \%$ for life satisfaction, and $5 \%$ for depression. Controlling for demographic factors and motor impairments resulted in negligible percentages of variance additionally explained by cognitive functioning. The percentages of explained variance were somewhat lower in the analyses with the separate cognitive domains and not significant for depression. Poor cognitive functioning was associated with reduced functional independence, social participation, depressive mood, and life satisfaction 1 year post; however, motor impairment was a stronger determinant of long-term QoL than cognitive functioning. Key Words: Cerebrovascular accidentcognition disorder-quality of life-neuropsychological test.
\end{abstract}

(C) 2011 by National Stroke Association

Quality of life (QoL) problems are experienced by many people who survive a stroke but are confronted with residual physical and cognitive impairments. ${ }^{1,2}$
Numerous studies have investigated associations between poststroke cognitive functioning and long-term QoL. ${ }^{1,3-12}$ These studies have yielded diverging results,
From the *Department of Stroke Rehabilitation, tCenter of Excellence in Rehabilitation Medicine, Rehabilitation Center De Hoogstraat, Utrecht, The Netherlands; $\ddagger$ Rudolf Magnus Institute for Neuroscience, University Medical Center Utrecht, Utrecht, The Netherlands; §Department of Rehabilitation, Academic Medical Center, Amsterdam, The Netherlands; $\uparrow$ Department of Experimental Psychology, Utrecht University, Utrecht, The Netherlands; |Department of Neurology, University Medical Centre, Utrecht, The Netherlands; and ${ }^{* *}$ School for Mental Health and Neuroscience, Maastricht University, Maastricht, The Netherlands.
Received October 2, 2009; accepted February 5, 2010.

The authors have no conflict of interest statement.

Address correspondence to Clara L. M. Verhoeven, MSc, Rehabilitation Center De Hoogstraat, Rembrandtkade 10, 3583 TM Utrecht, The Netherlands. E-mail: k.verhoeven@dehoogstraat.nl.

$1052-3057 / \$$ - see front matter

(c) 2011 by National Stroke Association

doi:10.1016/j.jstrokecerebrovasdis.2010.02.018 
however; most revealed significant relationships between poor cognitive functioning and QoL, but others did not. $5,12,13$ Several studies using comprehensive neuropsychological test batteries found that only some of the cognitive functions tested were related to QoL. $4,9,12,14$ Some studies found bivariate relationships only, without adjusting for the influence of demographic factors and physical impairments on QoL, whereas studies using multivariate analyses found that some of the significant bivariate relationships were no longer significant in regression analyses. $4,7,9,12,14$

Another problem is that the previous studies are difficult to compare, because they used different cognitive assessment strategies. The assessment of cognitive impairment ranged from scoring the presence of dementia ${ }^{1}$ to the use of general screening measures like the Mini Mental State Examination (MMSE), ${ }^{3,7}$ the use of a screening battery designed to measure several cognitive domains, ${ }^{8}$ and the use of comprehensive neuropsychological test batteries covering various cognitive domains. $4,6,9,12,14$

Studies also have used many different outcomes, which is not surprising given that QoL is a complex and multidimensional concept that covers both objective and subjective aspects of physical, mental, and social health and well being. ${ }^{15}$ QoL domains investigated include physical independence, ${ }^{9,12}$ independent living, ${ }^{10}$ participation, ${ }^{9,11}$ depression, ${ }^{6,13,16,17}$ health status or healthrelated QoL, 1,4,5,9,12 overall QoL, ${ }^{7}$ life satisfaction, ${ }^{8,11}$ and utility scores. $^{3}$ Because QoL is a multidimensional concept, selecting and measuring a number of key QoL domains might improve our understanding of the relationships between cognitive function and QoL by revealing differential relationships between various cognitive functions and various QoL domains.

Consequently, we conducted this study to investigate relationships between cognitive functioning and various QoL domains at 1 year poststroke, and also to examine the strengths of these relationships with and without adjustment for the influence of demographic factors and motor impairment.

Our research questions were as follows:

1. Is cognitive functioning bivariately related to different domains of QoL at 1 year poststroke?

2. Is cognitive functioning independently related to QoL domains after adjustment for the influence of demographic characteristics and motor impairments?

\section{Patients and Methods}

\section{Subjects and Procedures}

Patients consecutively admitted to the acute stroke units of 6 hospitals in The Netherlands were asked to participate. After informed consent was obtained, magnetic resonance imaging (MRI) was performed a mean of 11 days (standard deviation [SD] \pm 3.5 ) after the stroke. All neurologic examinations were done by a neurologist.
Other measures of functional status in the acute phase were collected by a trained research assistant at around day 5 after admission to the stroke unit. Whether to include or exclude a subject was determined during the acute phase. Subjects included had a nonlacunar firstever stroke of the anterior cerebral artery (ACA), medial cerebral artery (MCA), or posterior cerebral artery (PCA), were aged 18-85 years, were in a stable neurologic condition 1 week poststroke, and had a premorbid Barthel Index $(\mathrm{BI}) \geq 18 .{ }^{18}$ Excluded were subjects with an infratentorial lesion, multiple infarctions, a borderzone infarction, or a lacunar infarction visible on the MRI scan after 1 week, as well as those with prestroke cognitive limitations. ${ }^{19}$

Each subject included in the study was examined at home at 1 year poststroke. Cognitive functioning was assessed by a neuropsychologist. If the subject exhibited aphasia, neglect, or other severe cognitive impairment, the neuropsychologist determined which test could be reliably administered and interrupted administration if necessary. In addition, a trained test assistant assessed the subject's functional status and administered the questionnaires. A healthy and relevant control group was included to ensure that normative data were obtained for the cognitive tests. ${ }^{9}$ The Medical Ethics Committees of all participating hospitals approved the research protocol.

Motor impairment was measured with the Motricity Index (MI). ${ }^{20} \mathrm{MI}$ scores range from 0 (complete paralysis) to 100 (normal motor functioning) and are calculated by adding the weighted scores for the 3 movements of each upper and lower limb and a total score for normal functioning. The choice of relevant QoL domains, functional independence, participation, depressive mood, and life satisfaction was based on the model of Post and Noreau. ${ }^{15}$ Functional independence was assessed with the BI, a 10-item measure including self-care, mobility, and continence, with a total score between 0 (completely dependent) and 20 (independent). ${ }^{18}$ Level of participation was measured with the Frenchay Activities Index (FAI), a 15item measure covering household activities and outdoor activities, with a total score between 0 (no participation) and 45 (high participation). ${ }^{21}$

Depressive mood was assessed with the Center for Epidemiological Studies Depression Scale (CES-D), a selfreport measure of depressive symptoms with 20 items and a total score between 0 (no depressive symptoms) and 60 (high level of depressive symptoms). ${ }^{22}$ The CES-D is a valid screening instrument for depression, and its cutoff point of 16 has demonstrated good sensitivity (86\%) and specificity $(90 \%)$ in stroke patients. ${ }^{23,24}$

Life satisfaction was assessed with the Life Satisfaction Questionnaire (LiSat-9), which rates the degree of satisfaction with life as a whole and with 8 life domains, including self-care ability, leisure activities, and family life. The total score is the mean of the item scores and ranges from 1 (very unsatisfied) to 6 (very satisfied). ${ }^{25}$ 
The selection of relevant cognitive domains (ie, language, attention and psychomotor function, memory, visuoperception and neglect) was based on earlier studies. ${ }^{12}$ For the language domain, the Token Test (short form ${ }^{26}$ was used to measure language comprehension, and the Boston Naming Test (short form) ${ }^{27}$ provided information about language production, particularly naming ability.

For attention and psychomotor function, parts A and B of the Trail-Making Test (TMT-A and TMT-B) ${ }^{28}$ were used to measure psychomotor speed and attention. Several participants were able to complete the TMT-A, but not the TMT-B. Because the TMT-B measures a more complex aspect of attention than the TMT-A, failing on the TMT-B after completing the TMT-A can likely be attributed to impaired attention rather than any other cognitive impairment. For that reason, a subject who was able to complete part A but not part B was assigned the maximum score of 300 seconds on the TMT-B.

The Rey Auditory-Verbal Learning Test ${ }^{29}$ was used to measure immediate and delayed recall and delayed recognition. Visual memory was assessed with the Doors test. ${ }^{30}$ In this subtest of the Baddeley Doors and People Test, 12 target items (ie, a photograph of a door) are presented consecutively for 3 seconds and given a label. After the presentation, the subject is asked to recognize the correct target from 12 cards consisting of the target item and 3 distracters (photographs of other doors). These cards are presented in a different order than the first presentation of the target items. A mark is given for each correct response, yielding a maximum score of 12 .

For visuoperception, the Benton Facial Recognition Test $(B F R T)^{31}$ was used to evaluate the ability to perceive and match faces. Visuospatial perception was assessed with the Judgment of Line Orientation Test (JLO). ${ }^{31}$

A letter cancellation task was used to detect neglect. ${ }^{32}$ This task consists of a page with 465 randomly placed letters of normal reading size, 40 of which are the target items (the "O"). The subject is instructed to cross out the target items. The number and location of omissions demonstrates the presence or absence of neglect.

\section{Analyses}

The single-sample Kolmogorov-Smirnov test was used to examine the score distributions of the dependent variables. Because the BI score demonstrated a strong ceiling effect $(P<.001)$ that could not be corrected by score transformation, the BI was dichotomized using the median score of 17 as the cutoff. Individuals with a BI score $>17$ generally require minimal or no assistance with daily activities. ${ }^{33}$ The score distributions of the FAI, CES-D, and LiSat-9 did not deviate significantly from the normal distribution and thus were not dichotomized, to prevent unnecessary loss of information.
Raw test scores of the cognitive tests were transformed to $z$-scores using the means and SDs of the control group. The scores of the Boston Naming Test were first corrected for age and education according to norms available for the Dutch population. ${ }^{34}$ No control group data were available for the Doors Test, so the $z$-scores were based on the norm data described in the manual (mean, $10 \pm 3$ ). The scores of the TMT-A, TMT-B, and the letter cancellation task were multiplied by -1 , so that higher scores on all neuropsychological tests indicate better cognitive functioning. Subsequently, $z$-scores of tests belonging to the same cognitive domain were averaged to obtain scores for the cognitive domains of language, attention and psychomotor function, memory and visuoperception. Impairment in these cognitive domains was defined as a score that differed from the mean score of the control group at a .05 level of significance $(z<-1.65) .{ }^{9}$ For neglect, comparing scores to those of a control group was not possible; thus, neglect was considered to be present if $>4$ items were omitted on the left or right side of the letter cancellation task. A total cognition score was calculated by averaging the $z$-scores of the cognitive domains. For neglect, a $z$-score of -1.65 was used when there were $>4$ omissions, to allow incorporation of all cognitive domains.

Bivariate relationships between cognition, demographic data, MI, and the QoL variables were analyzed using Pearson correlation coefficients for the FAI, CES-D, and LiSat-9 and Somers' $D$ for the BI.

Linear regression analyses were applied to analyze possible determinants of the FAI, CES-D, and LiSat-9. Logistic regression analysis was applied to analyze possible determinants of the BI. In the first step, only the total cognition score was entered in each analysis. In the second step, the variables age, sex, and education were entered, and in the third and final step, MI was entered. After each step, the percentage of variance explained by the variables remaining in the final model was computed. This procedure was repeated with the separate cognitive domains entered into the analyses instead of the total cognition score. All statistical analyses were performed using SPSS version 15.0 (SPSS Inc, Chicago, IL).

\section{Results}

Of the 111 subjects included in the study, 19 (21.1\%) dropped out before the 1-year follow-up; 9 died, 4 had another stroke incident, 2 developed a serious comorbidity that affected functioning, and 4 decline to participate. This left 92 subjects (45 men and 47 women) available for analysis. Half of the subjects $(52.7 \%)$ had a left hemispheric stroke, as determined by lesion localization on MRI, and $21.6 \%$ had a hemorrhagic component. In $61.1 \%$ of the subjects the lesion location was primarily cortical. More than one-third (35.2\%) of the subjects had cerebral hyperintensities indicating additional white matter lesions. In the second week after stroke, the mean BI 
score of this group was $9.8 \pm 6.7$, the mean National Institutes of Health Stroke Scale score was $10.7 \pm 5.7$, and the mean MMSE score was $25.4 \pm 4.3$.

Subjects were examined at a mean time of $377 \pm 21$ days poststroke. At follow-up, mean age was $63.7 \pm 14.4$ years. Fifty-three subjects (58\%) had a low or intermediate level of education. Of all subjects, $22.8 \%$ lived in an institution with 24-hour professional care (ie, nursing home). The mean BI score at 1 year poststroke was $16.3 \pm 5.3$, and $62 \%$ of the subjects were functionally independent (BI $>17$ ). The mean MI score was $71.4 \pm 33.9$, mean FAI score was $17.5 \pm 11.6$, mean CES-D score was $17.4 \pm 9.2$, and mean LiSat- 9 score was $4.2 \pm 0.9$. The correlations between the outcome measures ranged from moderate (ie, CES-DBI, -0.32, $P<.01$; CES-D-FAI, $-0.26, P<.05$ ) to strong (ie, CES-D-LiSat-9, -0.68, $P<.01$; FAI-BI, 0.66, $P<.01$ ). The correlations between education and the cognitive domains varied from low (ie, education-neglect, $-0.14, P<.01$ ) to moderate (ie, education-visuoperception, $0.43, P<.01$ ). Correlations between motor functioning (based on the $\mathrm{MI})$ and cognitive functioning ranged from $0.22(P<.05)$ for language up to 0.50 for neglect $(P<.01)$.

A group of 77 healthy controls $(60 \%$ female $)$ was available for analysis. The mean age of the healthy control group was $62.3 \pm 16.8$ years, and the mean level of education was $4.5 \pm 2.4$ on a scale of 1-7 (low, 1-2; intermediate, 3-5; high, 6-7).

\section{Cognitive Functioning}

Table 1 presents the raw scores on the neuropsychological tests for the subjects, along with the scores of the healthy controls. Using a cutoff of 24, the MMSE scores show that $16.5 \%$ of the subjects had impaired performance. The percentage of impaired performance in the cognitive domains varied between 19.3\% (neglect) and 72\% (attention and psychomotor function). Almost half of the participants $(42.7 \%)$ were impaired on the total cognition score (Table 2).

\section{Bivariate Relationships}

Table 3 presents the associations between QoL domains and demographic variables, MI, and cognitive domains. The total cognition score correlated significantly with all QoL domains, most strongly with the FAI $(0.63 ; P<.01)$. All cognitive domain scores were significantly associated with FAI and BI scores. Attention and psychomotor function, visuoperception, and neglect were significantly associated with the LiSat-9, and language and visuoperception were significantly associated with the CES-D. Visuoperception was correlated with all QoL domains. Language, attention and psychomotor function and neglect were correlated to 3 domains, and memory was correlated to 2 domains.

\section{Multivariate Relationships}

Table 4 gives the results of the regression analyses for the BI, FAI, CES-D, and LiSat-9 scores. The total cognition score alone explained $19.1 \%$ of the variance in the BI (step 1). Demographic variables and MI were significant determinants of the BI score; in the final model, the MI score and age together explained $67.6 \%$ of the variance (step 3 ).

Table 1. Descriptive data concerning the participants and the healthy controls: Number of subjects, mean, and SD for each neuropsychological test

\begin{tabular}{|c|c|c|c|c|c|c|}
\hline \multirow[b]{2}{*}{ Test } & \multicolumn{3}{|c|}{ Participants } & \multicolumn{3}{|c|}{ Controls } \\
\hline & $\mathrm{n}$ & Mean & $\mathrm{SD}$ & $\mathrm{n}$ & Mean & SD \\
\hline \multicolumn{7}{|l|}{ Language } \\
\hline Token test & 79 & 13.4 & 5.3 & 77 & 18.4 & 2.9 \\
\hline Boston Naming Test & 85 & 145.5 & 29.7 & 77 & 80.5 & 10.5 \\
\hline \multicolumn{7}{|c|}{ Attention and psychomotor function } \\
\hline TMT-A & 82 & 75.7 & 49.3 & 77 & 32.9 & 13.2 \\
\hline TMT-B & 82 & 146.4 & 80.6 & 77 & 51.5 & 25.4 \\
\hline \multicolumn{7}{|l|}{ Memory } \\
\hline RAVLT immediate recall & 79 & 29.6 & 12.6 & 77 & 42.9 & 12.6 \\
\hline RAVLT delayed recall & 79 & 5.5 & 3.4 & 76 & 8.7 & 3.2 \\
\hline RAVLT recognition & 80 & 28.6 & 3.8 & 77 & 28.6 & 2.2 \\
\hline Doors test & 88 & 8.1 & 3.5 & NA & NA & NA \\
\hline \multicolumn{7}{|l|}{ Visual perception } \\
\hline BFRT & 86 & 41.2 & 6.0 & 77 & 45.9 & 5.8 \\
\hline JLO & 84 & 10.3 & 3.5 & 76 & 11.9 & 2.6 \\
\hline \multicolumn{7}{|l|}{ Neglect } \\
\hline Letter Cancellation test & 88 & 4.4 & 8.6 & NA & NA & NA \\
\hline
\end{tabular}

All scores presented are the number of correct answers, except for TMT-A and TMT-B (time in seconds) and for Neglect (number of omissions). The Doors test and Letter Cancellation Test were not administered to the control group. 
Table 2. Number of participants, mean, SD, and percentage impairment per cognitive domain and for the total cognition score

\begin{tabular}{lcccc}
\hline \multicolumn{1}{c}{ Cognitive domain } & $\mathrm{n}$ & Mean & SD & \% impairment \\
\hline Language & 83 & -1.70 & 2.02 & 41 \\
Attention and psychomotor function & 82 & -4.27 & 3.49 & 72 \\
Memory & 88 & -0.87 & 0.88 & 21.6 \\
Visuoperception & 88 & -0.75 & 1.06 & 23.9 \\
Neglect & 88 & & & 19.3 \\
Total cognition & 89 & -1.57 & 1.22 & 42.7 \\
\hline
\end{tabular}

Percent impairment based on cutoff point of $z$ score $<-1.65$ (Language, Attention and psychomotor function, Visuoperception, and Memory), number of omissions (Neglect).

The total cognition score alone explained $40 \%$ of the variance in the FAI (step 1). After inclusion of all variables, total cognition, age, sex, education, and MI together explained $66.6 \%$ of the variance. For the LiSat-9 score, $9.3 \%$ of the variance was explained by total cognition (step 1). After inclusion of all variables, total cognition and MI together explained $23.3 \%$ of the variance in the LiSat-9. For the CES-D, total cognition alone explained $5.9 \%$ of the variance, and total cognition, sex, and education together explained $15.3 \%$ of the variance.

Table 5 presents the results of the regression analyses for the BI, FAI, and LiSat-9 scores and the separate cognitive domains. A regression analysis performed to predict the CES-D demonstrated no significant relationships and thus was not included in the table. Cognitive domains alone explained $21.3 \%$ of the variance in BI (step 1). Demographic variables and MI were significant determinants of the BI score; in the final model, MI score and age together explained $61.6 \%$ of the variance (step 3 ).

The cognitive domains alone explained $47.5 \%$ of the variance in the FAI (step 1). After inclusion of all variables, attention and psychomotor function, sex, education, and MI together explained $61.9 \%$ of the variance $(P<.001)$.
For the LiSat-9 score, $7.8 \%$ of the variance was explained by the cognitive domains alone (step 1). After inclusion of all variables, neglect $(P=.077)$ and $\mathrm{MI}(P=.054)$ together explained $12.3 \%$ of the variance in the LiSat-9 $(P<.01)$.

\section{Discussion}

Our findings show that impaired cognitive functioning is related to decreased QoL at 1 year poststroke, that this relationship is strongest for social participation and weakest for depressive mood, and that the predictive value (ie, amount of explained variance) of cognitive functioning diminishes after adjusting for demographic characteristics and motor impairment. These results suggest directions for further research on the important and complex issue of the association between cognitive impairment and QoL after stroke.

\section{Cognitive Impairment and QoL}

Here $79 \%$ of the subjects had an impairment in one or more cognitive domains. This percentage was similar to the $78 \%$ found in another study in a group with similar levels of physical disability. ${ }^{10}$ Nys et $\mathrm{al}^{17}$ found a lower

Table 3. Bivariate analyses of the cognitive domains, total cognition score, demographic variables and motor impairments, and dependent variables

\begin{tabular}{lcccc}
\hline & BI & FAI & CES-D & LiSat-9 \\
\hline Language & $0.13^{*}$ & $0.41^{* *}$ & $-0.23^{*}$ & 0.20 \\
Attention and psychomotor function $\dagger$ & $0.17^{* *}$ & $0.60^{* *}$ & -0.21 & $0.28^{*}$ \\
Memory & $0.17^{* *}$ & $0.56^{* *}$ & -0.12 & 0.21 \\
Visuoperception & $0.22^{* *}$ & $0.57^{* *}$ & $-0.32^{* *}$ & $0.28^{* *}$ \\
Neglect & $0.58^{* *}$ & $0.52^{* *}$ & 0.17 & $0.35^{* *}$ \\
Total cognition & $0.21^{* *}$ & $0.63^{* *}$ & $-0.24^{*}$ & $0.31^{* *}$ \\
Age & $-0.18^{* *}$ & $-0.36^{* *}$ & 0.15 & 0.04 \\
Sex & -0.19 & -0.09 & $0.27 *$ & -0.07 \\
Education & $0.24^{* *}$ & $0.44^{* *}$ & -0.11 & 0.11 \\
Motor functioning & $0.42^{* *}$ & $0.65^{* *}$ & -0.14 & $0.40^{* *}$ \\
\hline
\end{tabular}

BI dichotomized: High score means good functional status; associations were tested with Somers' $D$.

$* P<.05$.

$* * P<.01$.

$\dagger$ The $z$-scores for attention and psychomotor function and neglect were multiplied by -1 to create the same direction for all correlations. 
prevalence of cognitive impairments $(31 \%)$ at 6 months after stroke; however, their study did not assess attention and psychomotor function, and $72 \%$ of our respondents showed impairments in this domain. This percentage is high compared with that reported by van Zandvoort et $\mathrm{al}_{;}{ }^{12}$ however, we included the more difficult TMT-B, because this test was found to predict $\mathrm{QoL}$ in a previous study. ${ }^{4}$ In addition, we imputed the worst possible score (z-score, 9.78) on the TMT-B if participants were able to complete part A only, thereby providing a more realistic estimate of the prevalence and seriousness of attention and psychomotor problems in our sample.

We found significant bivariate associations between all cognitive domains and functional independence. Regression analyses demonstrated that memory and neglect remained determinants of functional status after inclusion of demographic characteristics, but that none of the cognitive domains was an independent determinant of functional independence after inclusion of demographic characteristics and motor functioning. One previous study also found 6 out of 7 cognitive domains to be bivariately significant; however, their regression analysis identified only visual memory and neglect as independent determinants of functional independence, and did not include a score for motor impairments. ${ }^{9}$

In the present study, all cognitive domains showed a significant bivariate association with social participation. The first regression analysis, including only the cognition variables, identified attention and psychomotor function, memory, and visuoperception as significant cognitive determinants. After adding the demographic variables and motor functioning to the analysis, only attention and psychomotor function remained a significant determinant of social participation. Other studies reported similar findings; most cognitive domains measured showed significant bivariate correlations with participation, but regression analyses with adjustment for motor impairments yielded a significant relationship for only one domain or for no domains. ${ }^{9,11}$

Although the domains of visuoperception and language were significantly related to depressive mood, the regression analysis with the total cognition score explained only a small percentage of the variance. The analyses with the separate cognitive domains yielded no significant results. The literature contains conflicting results; whereas several studies reported a relationship between cognitive impairment and depression, ${ }^{6,16,17,35}$ others did not. ${ }^{13,36}$ Only one study included a regression analysis of relationships between cognitive functioning and depressive mood. ${ }^{17}$ Neglect was a significant determinant of depressive mood, but again these relationships were not adjusted for motor functioning.

In the present study, several cognitive domains were related to life satisfaction. In the first 2 steps of the regression analysis, however, only neglect was a significant determinant. After adjustment for motor functioning, 
Table 5. Backward regression analyses with step 1 (cognitive domains only), step 2 (cognitive domains and demographic variables), and step 3 (cognitive domains, demographic variables, and motor impairments)

\begin{tabular}{|c|c|c|c|c|c|c|c|c|c|}
\hline & \multicolumn{3}{|c|}{ BI (odds ratio) } & \multicolumn{3}{|c|}{ FAI (beta) } & \multicolumn{3}{|c|}{ LiSat-9 (beta) } \\
\hline & 1 & 2 & 3 & 1 & 2 & 3 & 1 & 2 & 3 \\
\hline Language & & & & & 0.17 & & & & \\
\hline $\begin{array}{l}\text { Attention and psychomotor } \\
\text { function }\end{array}$ & & & & $0.27 *$ & $0.26^{*}$ & $0.37 * *$ & & & \\
\hline Memory & & $2.15^{*}$ & & $0.35 * *$ & $0.25^{*}$ & & & & \\
\hline Visuoperception & 1.77 & & & $0.25^{*}$ & $0.24 *$ & & & & \\
\hline Neglect & $4.99 *$ & $5.97^{*}$ & & & 0.18 & & $0.28 *$ & $0.28 *$ & 0.21 \\
\hline Age & - & & $0.90 *$ & - & & & - & & \\
\hline Sex & - & $0.27 *$ & & - & $0.21 *$ & $0.23 * *$ & - & & \\
\hline Education & - & & & - & 0.18 & $0.27 * *$ & - & & \\
\hline Motor functioning & - & - & $1.08 * *$ & - & - & $0.42 * *$ & - & - & 0.23 \\
\hline $\begin{array}{l}\text { Nagelkerke (BI)/ R-square } \\
\quad \text { (FAI, LiSat-9) }\end{array}$ & 21.3 & 27.3 & 61.6 & 47.5 & 48.4 & 61.9 & 7.8 & 7.8 & 12.3 \\
\hline
\end{tabular}

BI dichotomized: High score means not impaired and low score means impaired in functional dependence. Neglect dichotomized: High score means no neglect present and low score means neglect present.

-, not entered in the analysis.

$* P<.05$.

$* * P<.01$

neglect and motor functioning together explained a significant proportion of the variance, although both were only borderline significant ( $P=0.05-0.10$ ) determinants.

One previous study identified reasoning and memory as significant determinants of life satisfaction at 15 months poststroke, after adjusting for level of activity. ${ }^{11}$ Another study found language to be a significant determinant of life satisfaction, but the researchers did not adjust for motor function. ${ }^{8}$

Comparing our findings with the literature indicates that data demonstrating associations between cognitive impairments and QoL are seriously influenced by adjustment for motor function, and that most previous studies presented unadjusted results. Not adjusting for motor function could result in overestimation of the importance of cognitive impairments for QoL. However, adjusting for the influence of motor impairments may also lead to an underestimation of this relationship, as the independently predicted variance does not include the proportion of the variance jointly explained by both variables (cognitive and motor impairments). Studies with stroke patients having cognitive impairments and having no motor impairments will probably provide a better estimation of this relationship.

Another interesting finding of our study is that the objective dimensions of QoL (ie, functional independence, social participation) showed more and stronger bivariate associations with cognitive impairments compared with the more subjective dimensions (ie, depressive mood, life satisfaction). One possible explanation for this finding is our use of neuropsychological tests to assess cognitive impairments. A previous study suggested that associations between self-reported cognitive problems and depressive mood are stronger than those between neuropsychological test results and depressive mood. ${ }^{37}$ It is also possible that our long duration of follow-up had some influence; some previous studies with a long-term follow-up also found no association between cognition and depression. ${ }^{37,38}$ It is possible that after 1 year, the subjects had adapted to their situation, resulting in a "response shift" in their subjective evaluation of their situation that weakened the association between "objective" neuropsychological functioning and "subjective" mood and life satisfaction. ${ }^{39,40}$ Other factors, not included in this study, also can influence mood and life satisfaction. One of these factors might be the way in which a subject copes with his or her situation and disabilities. ${ }^{41}$

\section{Study Limitations}

One limitation of the present study lies in the coverage of cognitive domains. No measurements of executive functioning were used, for instance, even though it is known that even mild or moderate impairments in this domain can cause difficulties in the ability to plan and develop goals in life. ${ }^{3,9}$ Furthermore, the Doors Test measures only the recognition of visual information and does not test the stages of recall.

The inclusion of 3 different types of stroke might have obscured our findings, but the number of subjects per type was mostly too small to allow an analysis of the influence of lesion location. Whether or not treatment had been provided (and what kind) between the acute phase and the examination at 1 year poststroke also might 
have a moderating effect on the outcome measures, which we did not assess.

The final limitation relates to the question of whether or not our results can be generalized. The number of patients who declined to participate on admission to the stroke unit is unknown, and this group might have differed from the subjects who participated in the study.

\section{Conclusion}

Our data indicate that cognitive impairments were related to all of the following QoL domains at 1 year poststroke: functional independence, social participation, mood, and life satisfaction. However, motor functioning was a stronger determinant of long-term QoL than cognitive functioning. These findings stress the need to consider both motor and cognitive rehabilitation when addressing aspects of QoL in rehabilitation programs.

\section{References}

1. Sturm JW, Donnan GA, Dewey HM, et al. Quality of life after stroke: the North East Melbourne Stroke Incidence Study (NEMESIS). Stroke 2004;35:2340-2345.

2. Kwakkel G, Kollen B, Lindeman E. Understanding the pattern of functional recovery after stroke: facts and theories. Restor Neurol Neurosci 2004;22:281-299.

3. Haacke C, Althaus A, Spottke A, et al. Long-term outcome after stroke: evaluating health-related quality of life using utility measurements. Stroke 2006;37:193-198.

4. Hochstenbach J, Anderson P, van Limbeek J, et al. Is there a relationship between neuropsychologic variables and quality of life after stroke? Arch Phys Med Rehabil 2001;82:1360-1366.

5. Jonkman EJ, de Weerd AW, Vrijens NL. Quality of life after a first ischemic stroke: long-term developments and correlations with changes in neurological deficit, mood, and cognitive impairment. Acta Neurol Scand 1998;98:169-175.

6. Kauhanen ML, Korpelainen JT, Hiltunen P, et al. Poststroke depression correlates with cognitive impairments and neurological deficits. Stroke 1999;30:1875-1880.

7. Kwa VI, Limburg M, de Haan RJ. The role of cognitive impairment in the quality of life after ischaemic stroke. J Neurol 1996;243:599-604.

8. Larson EB, Kirschner K, Bode RK, et al. Brief cognitive assessment and prediction of functional outcome in stroke. Top Stroke Rehabil 2003;9:10-21.

9. Nys GM, van Zandvoort MJ, de Kort PL, et al. The prognostic value of domain-specific cognitive abilities in acute first-ever stroke. Neurology 2005;64:821-827.

10. Tatemichi TK, Desmond DW, Stern Y, et al. Cognitive impairment after stroke: frequency, patterns, and relationship to functional abilities. J Neurol Neurosurg Psychiatry 1994;57:202-207.

11. Visser-Keizer AC. The impact of emotional and cognitive changes after stroke: a longitudinal community-based study [dissertation]. Groningen, The Netherlands: University Library Groningen, 2004.

12. van Zandvoort MJ, Kessels RP, Nys GM, et al. Early neuropsychological evaluation in patients with ischemic stroke provides valid information. Clin Neurol Neurosurg 2005; 107:385-392.
13. Leentjes AF, Aben I, Lodder J, et al. General and diseasespecific risk factors for depression after ischemic stroke: a two-step Cox regression analysis. Int Psychogeriatr 2006;29:1-9.

14. Novack TA, Haban G, Graham K, et al. Prediction of rehabilitation outcome from psychological screening. Arch Phys Med Rehabil 1987;68:729-734.

15. Post M, Noreau L. Quality of life after spinal cord injury. J Neurol Phys Ther 2005;29:139-146.

16. Hackett ML, Anderson CS. Predictors of depression after stroke: a systematic review of observational studies. Stroke 2005;31:2296-2301.

17. Nys GM, van Zandvoort MJ, van der Worp HB, et al. Early cognitive impairment predicts long-term depressive symptoms and quality of life after stroke. J Neurol Sci 2006;247:149-156.

18. Collin C, Wade DT, Davies S, et al. The Barthel ADL Index: a reliability study. Int Disabil Stud 1988;10:61-63.

19. Schiemanck SK, Post MW, Kwakkel G, et al. Ischemic lesion volume correlates with long-term functional outcome and quality of life of middle cerebral artery stroke survivors. Restor Neurol Neurosci 2005;23:257-263.

20. Collen FM, Wade DT, Bradshaw CM. Mobility after stroke: reliability of measures of impairments and disability. Int Disabil Stud 1990;12:6-9.

21. Holbrook M, Skilbeck CE. An activities index for use with stroke patients. Age Ageing 1983;12:166-170.

22. Radloff LS. The CES-D Scale: a self-report depression scale for research in the general population. Appl Psychol Measure 1977;1:385-401.

23. Shinar D, Gross CR, Price TR, et al. Screening for depression in stroke patients: the reliability and validity of the Center for Epidemiologic Studies Depression Scale. Stroke 1986; 17:241-245.

24. Parikh RM, Eden DT, Price TR, et al. The sensitivity and specificity of the Center for Epidemiologic Studies Depression Scale in screening for post-stroke depression. Int J Psychiatry Med 1988;18:169-181.

25. Fugl-Meyer AR, Bränholm IB, Fugl-Meyer KS. Happiness and domain-specific satisfaction in adult northern Swedes. Clin Rehabil Med 1991;36:4-11.

26. De Renzi E, Vignolo LA. The Token test: a sensitive test to detect receptive disturbances in aphasics. Brain 1962; 85:665-678.

27. Kaplan EF, Goodglass H, Weintraub S. The Boston Naming Test. 2nd ed. Philadelphia: Lea \& Febiger, 1983.

28. Corrigan JD, Hinkeldey NS. Relationships between parts A and B of the Trail-Making Test. J Clin Psychol 1987; 43:402-408.

29. Rey A. L'Examen Clinique en Psychologie. Paris: Presses Universitaires de France, 1964.

30. Baddeley AD, Emslie H, Nimmo-Smith I. The Doors and People: A Test of Visual and Verbal Recall and Recognition. Bury St Edmunds, UK: Thames Valley Test Company, 1994.

31. Benton AL, HamsherdeS K, Varney NS, et al. Contributions to Neuropsychological Assessment: A Clinical Manual. New York: Oxford University Press, 1983.

32. van Heugten CM, Huygelen K, van der Sande P. Cognitieve screening bij CVA-patiënten in de revalidatie: normgegevens voor de klinische praktijk. Tijdschrift voor Gerontol Geriatr 2004;25:196-202.

33. Granger CV, Dewis LS, Peters NC, et al. Stroke rehabilitation: analysis of repeated Barthel Index measures. Arch Phys Med Rehabil 1979;60:14-17.

34. Heesbeen IME, van Loon-Vervoorn WA. Boston Benoemingstest: uitbreiding van de Nederlandse normen, gecorrigeerd voor opleiding en leeftijd. In: Heesbeen IME, ed. 
Diagnostiek en Herstelmeting van Taalproblemen na NietAangeboren. Veenendaal, The Netherlands: Universal Press, 2001.

35. Desmond WD, Remien RH, Moroney JT, et al. Ischemic stroke and depression. J Int Neuropsychol Soc 2003; 9:429-439.

36. Dam H. Depression in stroke patients 7 years following stroke. Acta Psychiatr Scand 2001;103:287-293.

37. Gerritsen MJ. Cognitive aftermath of ischemic stroke: a longitudinal community-based study [dissertation]. Groningen, The Netherlands: University Library Groningen, 2004.
38. House A, Dennis M, Warlow C, et al. The relationship between intellectual impairment and mood disorder in the first year after stroke. Psychol Med 1990;20:1681-1692.

39. Ahmed S, Mayo NE, Wood-Dauphinee S, et al. Using the Patient-Generated Index to evaluate response shift post-stroke. Qual Life Res 2005;14:2247-2257.

40. Schwartz CE, Sprangers MA. Methodological approaches for assessing response shift in longitudinal health-related quality of life research. Soc Sci Med 1999;48:1531-1548.

41. Donnelan C, Hevey D, Hickey A, et al. Defining and quantifying coping strategies after stroke: a review. J Neurol Neurosurg Psychiatry 2006;77:1208-1218. 